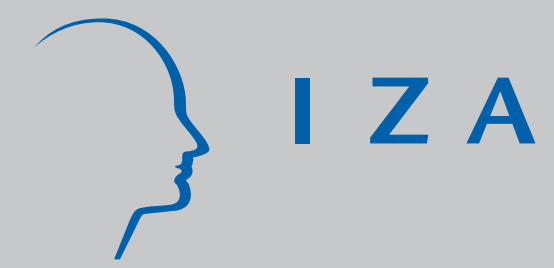

IZA DP No. 7999

A Validation Study of Transgenerational Effects of Childhood Conditions on the Third Generation Offspring's Economic and Health Outcomes Potentially Driven by Epigenetic Imprinting

Gerard J. van den Berg

Pia R. Pinger

February 2014 


\title{
A Validation Study of Transgenerational Effects of Childhood Conditions on the Third Generation Offspring's Economic and Health Outcomes Potentially Driven by Epigenetic Imprinting
}

\author{
Gerard J. van den Berg \\ University of Mannheim, \\ IFAU-Uppsala, VU University Amsterdam and IZA \\ Pia R. Pinger \\ University of Bonn \\ and IZA
}

Discussion Paper No. 7999

February 2014

IZA

P.O. Box 7240

53072 Bonn

Germany

Phone: +49-228-3894-0

Fax: +49-228-3894-180

E-mail: iza@iza.org

Any opinions expressed here are those of the author(s) and not those of IZA. Research published in this series may include views on policy, but the institute itself takes no institutional policy positions. The IZA research network is committed to the IZA Guiding Principles of Research Integrity.

The Institute for the Study of Labor (IZA) in Bonn is a local and virtual international research center and a place of communication between science, politics and business. IZA is an independent nonprofit organization supported by Deutsche Post Foundation. The center is associated with the University of Bonn and offers a stimulating research environment through its international network, workshops and conferences, data service, project support, research visits and doctoral program. IZA engages in (i) original and internationally competitive research in all fields of labor economics, (ii) development of policy concepts, and (iii) dissemination of research results and concepts to the interested public.

IZA Discussion Papers often represent preliminary work and are circulated to encourage discussion. Citation of such a paper should account for its provisional character. A revised version may be available directly from the author. 


\section{ABSTRACT \\ A Validation Study of Transgenerational Effects of Childhood Conditions on the Third Generation Offspring's Economic and Health Outcomes Potentially Driven by Epigenetic Imprinting*}

At the crossroads of economics and human biology, this paper examines the extent to which pre-puberty nutritional conditions in one generation affect productivity-related outcomes in later generations. Recent studies have found a negative association between conditions at ages 8-12 and the grandchild's over-all and cardiovascular and diabetes mortality in a single historical dataset. It has been argued that this association reflects epigenetic imprinting, which has been corroborated in animal studies. We provide an external validation by analyzing the impact of the German famine of 1916-1918 on children and grandchildren of those exposed to the famine at ages 8-12. Our findings support and extend the evidence so far. Among the third generation, males (females) tend to have higher mental health scores if their paternal grandfather (maternal grandmother) was exposed. We do not find robust effects on the probability of obtaining an upper secondary education.

JEL Classification: $\quad$ I12, J11

Keywords: famine, transgenerational transmission, epigenetics, mental health, education, long-run effects, nutrition, intergenerational effects, slow-growth period

Corresponding author:

Gerard J. van den Berg

Department of Economics

University of Mannheim

L7, 3-5

68131 Mannheim

Germany

E-mail: vandenberg@uni-mannheim.de

\footnotetext{
* We thank Denny Vågerö, George Davey Smith, Jim Heckman, Anders Björklund, Timo Hener, JeanMarc Robin and participants of the IZA Summer School for useful comments.
} 


\section{Introduction}

In this paper we validate and extend findings in a recent set of exciting studies on the transgenerational impact of nutritional shocks, where the mechanism plausibly runs via epigenetic imprinting. Recently, epigenetics has become a focal point in medical, biological and epidemiological research on the long run effects of nutrition, stress and other early life circumstances (see Gräff and Mansuy, 2008, Masterpasqua, 2009, Lundborg and Stenberg, 2010, Hochberg et al., 2011, Kuzawa and Thayer, 2011, and Low et al., 2012, for overview articles). Epigenetics is defined as the process by which patterns of gene expression are modified through methylation of the chromatin. Methylation involves the addition of a methyl group to the DNA base, which can turn down a gene's activity or switch it off entirely. This may be driven by environmental shocks such as exposure to malnutrition or stress. In this context, the possibility of transgenerational transmission is particularly interesting (see e.g. Harper, 2005, Gräff and Mansuy, 2008, Masterpasqua, 2009, Grossniklaus et al., 2013). Epigenetic imprinting is the phenomenon that shortly after conception, when stem cells are formed, some of the methyl tags from previous generations remain, causing heritable changes in gene functioning that are not driven by changes in the DNA sequence. Methyl markers are passed on through the germ line, with potentially different expressions of the maternal and paternal alleles in the offspring. Epigenetic modifications may depend on the sex of the parent who transmits it and can lead to transgenerational non-genetic inheritance of lifetime experiences across generations (Hochberg et al., 2011).

So far, most of the empirical evidence on epigenetic transgenerational transmission in mammals stems from animal experiments on mice and rats. Research with human probands is rare. Evidence focusing on later-life health and cognitive outcomes among offspring has to rely on non-experimental data, which leads to identification problems if parental conditions are endogenously related to unobserved characteristics that also influence outcomes in another way. To identify causal effects of food deprivation on subsequent generations, one needs to observe an exogenous shock in nutrition in the first generation as well as the relevant outcomes in subsequent generations. By now, a consensus has emerged that the study of transgenerational epigenetic inheritance that is induced by environmental shocks early in life requires the observation of at least three generations (see Grossniklaus et al., 2013). After all, effects of parental exposure to environmental shocks on their children's health may not only run through an epigenetic pathway but can have many other biological and behavioral explanations. Moreover, environmental shocks during pregnancy affect the mother, the fetus, and the fetus's primordial germ cells that will produce the grandchildren of the mother. Along these lines, it is particularly interesting to consider environmental shocks that may occur before reproductive ages, and to simultaneously analyze any effects 
of conditions faced by each grandparent.

The transmission over three generations of humans has only been studied in a single line of research papers using historical harvest data and church registers from the remote Överkalix region and connected regions in Northern Sweden (Bygren et al., 2001, Kaati, Bygren and Edvinsson, 2002, Pembrey, 2002, Pembrey et al., 2006, Kaati et al., 2007, Pembrey, 2010, Kaati, 2010). The authors find that low paternal grandfather's food supply in the years just before adolescence is associated with a lower mortality risk of grandsons, while low paternal grandmother's food supply is linked to a lower mortality risk of their granddaughters. Low food supply during the paternal grandfather's pre-puberty phase is also associated with lower third generation mortality from cardiovascular diseases, and higher diabetes mortality with a surfeit of food. The authors postulate that these effects are triggered by methylation of epigenetic marks during the ancestor's slow growth period (SGP) which took place at ages 8-10 for girls and at ages 9-12 for boys. The SGP is a sensitive period for the methylation of male sperm, and the authors hypothesize that the resulting methyl tags are transmitted to subsequent generations via epigenetic imprinting (Pembrey et al., 2006). This mechanism could be an evolved transgenerational response to developmental conditions. Adverse grandparental SGP conditions may then cause an improvement in the offspring's capability to face certain living conditions. Note that the sign of the effect within the first generation members' lives (as typically found in singlegeneration studies of long-run effects of early-life conditions) is then opposite to the sign of effects on certain later generations.

Due to its pathbreaking nature, the sequence of studies based on the Överkalix data has evoked great interest (see e.g. Zeisel, 2007, Gräff and Mansuy, 2008, Masterpasqua, 2009, Francis, 2011, Low et al., 2012, and Grossniklaus et al., 2013). At the same time it is fair to state that from a statistical point of view the analysis of the Överkalix data has some limitations. The studies consider up to three different degrees of food availability, among six ancestors (4 grandparents and 2 parents), during several parental and grandparental pre-adult age periods, and they examine their associations with several outcomes among grandchildren distinguished by sex. In the absence of strong theoretical priors, this amounts to the detection of a large number of associations. Even if no transgenerational transmission exists, a statistical analysis would typically result in a few number of false positives. Simply put, under the null hypothesis of no effects, and with a $5 \%$ test size, one finds an effect in $5 \%$ of the cases. Furthermore, samples of third generation members are rather small, ranging from ca. 100 to 300 individuals. For such a large number of parameters and given the small sample size, it is possible that the authors found effects that prove unimportant in other samples.

In this paper we aim to assess the external validity of these findings and extend the 
analysis to schooling and mental health outcomes. Specifically, we examine adult outcomes of subsequent generations following first-generation exposure to the severe German famine of 1916-1918 during the slow growth period. Clearly, any external validation requires unusual data, containing the date of birth of the first generation as well as relevant outcome measures for the third generation. Currently available administrative register data do not date back sufficiently far to meet these requirements. The same applies to longitudinal panel survey data. However, surveys may gather retrospective information obtained from second or third generation individuals about the relevant variables from the first generation. This is the approach we follow in this paper. We use data from the German Socioeconomic Panel (SOEP), a large longitudinal household panel since 1986 that is representative for the German population. The data allow us to identify whether a first generation of individuals (usually the parents of SOEP respondents) was exposed to the famine during the SGP. Furthermore, they contain information on a wide range of health information, longevity, education and economic outcomes for the second and third generation. We expect a firstgeneration individual's famine exposure during the SGP to be positively associated with favorable second and, in particular, favorable third generation outcomes. Furthermore, if famine exposure during SGP affects methylation of the male gametes but not the female ones, we expect only male SGP famine exposure to affect offspring results. ${ }^{1}$ Moreover, any causal impact of the famine, epigenetic or not, should be stronger for individuals who suffered from the famine for a longer period of time during their SGP.

As an exogenous shifter of nutritional conditions in the SGP, the German famine has several advantages. Specifically, it is well documented, it was severe, and it is sharply delineated in time. Yet, its usage also involves two limitations. First, following the famine, Germany was hit by the Spanish influenza, so that famine and influenza effects are hard to disentangle. Secondly, the famine was a single event, so that exposure during the SGP is equivalent to birth around 1907. Historical events, including World War II, may have affected the SGP famine cohort differently than adjacent cohorts. A number of additional empirical issues are common across studies of transgenerational effects. Notably, the study of three consecutive generations of a family requires that family members of the first two generations survive until reproductive ages and that they actually get children. This condition may be selective in that it relates to evolutionary fitness. We deal with many of these issues by carefully selecting the multigenerational sample and by estimating models that include a large number of indicators of secular changes in society and background controls.

Notice that the third-generation individuals in our sample are too young to have died of a natural cause so that we cannot study third-generation mortality outcomes. Instead, we

\footnotetext{
${ }^{1}$ The female oocytes fully develop during fetal development.
} 
examine adult height, adult mental health outcomes, as well as the highest attained level of education. Adult height is a universally accepted summary measure of pre-adult conditions that influence late-life health outcomes, notably longevity (Waaler, 1984, Steckel, 2008). It has been shown to be sensitive to nutritional deficits in the SGP (see van den Berg et al., 2009). Mental health has been shown to be particularly sensitive to epigenetic changes and it has been argued that it is also sensitive to epigenetic imprinting (see the above overview articles as well as McGowan et al. (2008) and Radtke et al. (2011)). Moreover, just like mortality and cardiovascular disease, the mental health outcome has been shown to be sensitive to early-life conditions (see Lumey et al. (2011) for a systematic overview of the evidence on the effects of in utero exposure to famines on schizophrenia and other mental disorders). Alternative potentially important health outcomes such as dementia or cardiovascular diseases are virtually absent in the third generation up to the end of the observation window, so that we cannot analyze them. Education is closely linked to cognitive and noncognitive skills and to social class. It is not clear why this outcome should reflect epigenetic imprinting, but as a determinant of economic well-being later in life it is interesting to consider it nevertheless. Moreover, cognitive skills at high ages have been shown to depend on early-life conditions, and the underlying mechanism may be related to the dependence of cardiovascular diseases on early-life conditions (Doblhammer et al., 2013). ${ }^{2}$ Concerning the second generation, we also investigate late-life mortality and adult height.

Like the Överkalix data, our data lack information on methylation patterns. This means that even if the transgenerational associations that we focus on all have the expected sign and significance, it can not be completely ruled out that other transgenerational mechanisms are also at play. In particular, exposure to a famine at pre-pubertal age may lead to more mature behavior. Elder (1999), investigating the impact of the Great Depression on children born in 1920-1921, finds that economic hardship around the age of 10 leads to more resilience and psychological strength. This may translate into a different style of upbringing of children. However, if such a mechanism is important then we expect it to lead to stronger effects on the second generation than on the third.

The paper proceeds as follows. Section 2 discusses recent developments in relevant branches of literature. Section 3 describes the 1916-1918 famine and summarizes the ex-

\footnotetext{
${ }^{2}$ To avoid confusion, notice that it is not an aim of our paper to study long-run effects of in-utero exposure to adverse conditions on the health of the individual him- or herself. As mentioned above, such conditions are known to lead to epigenetic changes (see e.g. Heijmans et al., 2008, and Tobi et al., 2009, for evidence on individuals exposed to the Dutch hunger winter around birth). It is not inconceivable that these are transgenerational. Heijmans et al. (2008) find different methylation levels of several genes almost 60 years after exposure, compared to unexposed siblings. Potentially, this could be inherited by subsequent generations.
} 
isting empirical evidence on its impact. Section 4 describes the empirical approach. We discuss a range of selection issues that may affect the results and that may have plagued the existing evidence. In Section 5 we describe our data. Section 6 presents our main findings. We investigate how results change if we extend the basic set of covariates with additional background variables that potentially account for non-biological pathways. We also present robustness checks in which the famine intensity is taken into account and its presumed time interval is adjusted. Section 7 concludes.

\section{$2 \quad$ Epigenetic Imprinting}

The logic behind epigenetics is evolutionary, but it potentially has important implications for the effects of health interventions and the economic modeling of human capital formation. Epigenetic marks play an important role in normal development because methylation patterns determine how stem cells develop into certain types of tissue which then maintain cell identity over the lifetime of an individual. In addition, epigenetic alterations cause gene regulation and changing phenotypes, and thus help cells to adopt to different purposes or environments in an evolutionary manner. Such epigenetic patterns are formed over the entire life-course (Fraga et al., 2005) and are strongly influenced by nutritional shocks (Heijmans et al., 2008, Tobi et al., 2009). Scientific evidence suggests that several health dimensions are related to epigenetic modifications. Epigenetics play an central role for the development of cancer cells and cardiovascular diseases and thus determine old-age mortality in humans (Ordovás and Smith, 2010, Jones and Baylin, 2002). Moreover, epigenetic changes influence mental health and cognition (Gräff and Mansuy, 2008, McGowan et al., 2008, Radtke et al., 2011).

Epigenetic imprinting and epigenetic inheritance imply that adaptive methylation patterns in one generation influence gene expression in the next. How such epigenetic transmissions or inheritance in humans works biologically is not fully resolved (Harper, 2005). Shortly after conception, when the first cell divisions are taking place, the stem cells are generally cleared of all methylation (Farooq, 2010, Mayer et al., 2000). However, if epigenetic modifications take place on the part of the genome that is genetically imprinted, this could explain sex-specific epigenetic inheritance. 'Imprinted genes' keep their methyl tags (about 1\% of genes), which function as a biological marker to flag up their maternal or paternal origin (Masterpasqua, 2009). Epigenetic inheritance may thus be a biological means for humans to adopt to changing environments and to transmit environmental information to the next generation.

Kaati and co-authors argue that the slow growth period of a child may be a sensitive 
period for epigenetic modifications on the male gametes and thus for epigenetic imprinting. ${ }^{3}$ In this period, the first sperm cells mature, which may make it an important period for the reprogramming of methylation imprints (Pembrey, 2002). The latter part of this period of childhood is also known as the 'fat spurt': growth is low and the body is accumulating reserves for in anticipation of the puberty-related development spurt (Marshall and Tanner, 1968, Gasser et al., 1994, Gasser, 1996). Therefore is plausible that limited food availability during pre-adolescence leads to worse pubertal development and to epigenetic modifications on the sperm or egg. ${ }^{4}$

It is perhaps fair to state that economists and social scientists are more interested in whether adverse experiences can be transmitted non-genetically from one generation to the next than in underlying biological mechanisms. ${ }^{5}$ Any non-genetic biological transmission of experiences would revolutionize economic thinking about transgenerational transmission and human capital accumulation in at least two ways. First, if life experiences were transmitted not only via upbringing and social circumstance but also biologically, from one generation to the next, this would imply that the costs and benefits of any policy measure would have to be re-evaluated to include such biological effects on subsequent generations. Second, it would imply that nature (genetic predisposition) and nurture (upbringing) are inseparable, and the long-fought nature-nurture debate would become obsolete. Future models of human capital investment would need to account for gene expressions and gene-environment interactions as well as for critical and sensitive periods of epigenetic transmission.

\section{The Famine}

The World War I famine which we use to study the effects of an exogenous variation in nutrition among the first generation was sharply delineated in time and extremely severe. In fact, it is said to be the severest famine experienced in Europe outside of Russia since Ireland's travail in the 1840s (Raico, 1989). At the end of the war, the German 'Reichsgesundheitsamt' (Health Office) calculated that 763,000 German civilians died from starva-

\footnotetext{
${ }^{3}$ Indeed, this growth period has previously been found to be a sensitive period for development. Sparén et al. (2004) find that a famine at this age increases cardiovascular problems later in life and Lindeboom et al. (2010) and van den Berg et al. (2009) find this age period to be a sensitive period for life expectancy and adult height, respectively.

${ }^{4}$ So, effects along the female line could also be driven by maternal nutrition during SGP. Indeed, mice models indicate that epigenetic imprinting may take place along the female germline (Cooney, 2006).

${ }^{5}$ For an overview of molecular genetics and economics see Lundborg and Stenberg (2009). For the role of epigenetics in psychology see Harper (2005).
} 
tion. ${ }^{6}$ The period of food scarcity started in June 1915 when bread began to be rationed. In early 1916, food rationing became severe. From 1916 to mid-1919, the German population on average had to live on less than 1500 calories per day (Starling, 1919). Because the portion of bran in the bread was very large, the caloric value was further reduced by about 15 to 20 percent. ${ }^{7}$ Most Germans had to live on a meagre diet of dark bread, slices of sausage without fat, three points of potatoes per week and turnips (Vincent, 1985). Table 1 displays an overview over the amount of food consumed during the famine as compared to prewar times. ${ }^{8}$ While these amounts are well below subsistence to begin with, the situation was aggravated by the mere length of the famine which started in 1916 and extended into 1919. At the height of the famine, purchasing foodstuffs on the black market was the only way to prevent starvation. Black market prices in cities skyrocketed (see Table A.2) and many families had to rely on excursions to the countryside to feed their children.

Four factors led to the extreme shortage of food. First, by mid-1916 the Allied Powers had successfully enacted a complete naval blockade of Germany restricting the maritime supply of raw materials and foodstuffs. Before the war Germany had imported one third of its food, but after the blockade Germany was cut from foodstuff imports of all sorts: fodder for livestock, grain and potatoes. The blockade continued even after the Armistice and until June 1919 to force Germany to sign the Treaty of Versailles. In fact, throughout 1919 rationing was maintained in many parts of the country at a rate of 1000-1300 calories per day (Vincent, 1985). ${ }^{9}$

Second, due to the general war mobilization, around $40 \%$ of the male agricultural labor force was absent, with a similar fraction of horses and cattle. This reduction in the male work force was not adequately compensated by employment of prisoners of war, women, adolescents and children (Huber and Fogel, 1920). As a consequence, between 1913 and 1919, annual production of crops, potatoes and milk decreased to about $50 \%$ when compared to pre-war levels (Blum, 2011).

Third, in the summer of 1916, the root crop and grain harvest were particularly bad and the potato crop failed almost completely. The latter was particularly detrimental, because much of the German food supply was based on potatoes and during the war more agricultural crop land had been shifted away from turnip cultivation and towards potatoes (Klein, 1968). The Winter of 1916-1917 thus marked the peak of the famine and is today

\footnotetext{
${ }^{6}$ The overall population of the German empire at that time was about 65 million. In addition there were about 2 million military deaths, who in a conventional ground-based war like World War I, were almost exclusively men of age 17-60.

${ }^{7}$ Typically, a man needs about 2500 calories a day and a women about 2000.

${ }^{8}$ For further evidence see Table A.1.

${ }^{9}$ The reason for continued food rationing was that even after the end of the blockade in June 1919 Germany could not import freely, since all funds had to be saved for war reparations.
} 
remembered as the 'turnip winter' (Steckrübenwinter), because the only food in sufficient supply during that winter were turnips.

Last, food storage was a concern. Before the war most of the potato crop was stored in the countryside and only supplied to the cities on demand. After the start of the war, transportation and dislocation became more difficult, and potatoes had to be stored in larger quantities by individuals unschooled in the proper techniques of storage, which led to spoilage and waste (Vincent, 1985).

Table 1: Food consumption before and during the famine

\begin{tabular}{l|cc} 
Item & Before War & During Famine \\
\hline \hline Calories & 2280 per day & 1313 per day \\
Protein & 70 g per day & $30-40$ g per day \\
Fat & 70 g per day & $15-20$ g per day \\
Bread & 225g a) per day & 160 g per day \\
Meat & 1050 g per week & 135 g per week \\
Potatoes & $100 \%$ & $71 \%$ \\
Grain & $100 \%$ & $53 \%$ \\
Sugar & $100 \%$ & $49 \%$ \\
Vegetable oil & $100 \%$ & $39 \%$ \\
Meat & $100 \%$ & $31 \%$ \\
Butter & $100 \%$ & $18 \%$ \\
Eggs & $100 \%$ & $3 \%$ \\
Pulse & $100 \%$ & $14 \%$ \\
Cheese & $100 \%$ & \\
\hline \hline
\end{tabular}

The famine had a large impact on the German population and in particular on young adolescents. On average, individuals lost 15-25 percent of their weight between 1916 and 1919 and height in the male population born in the period between 1914 and 1917 is around $1.5 \mathrm{~cm}$ less than for adjacent cohorts (Blum, 2011). ${ }^{10}$ Children were less likely to die than adults, but often suffered from hunger-diseases such as edema, tuberculosis, rickets,

\footnotetext{
${ }^{10}$ Individuals who had lost 30 percent or more mostly died.
} 
influenza, scurvy, and keratomalacia (Roesle, 1928). ${ }^{11}$ Under-consumption of food during that time was particularly dramatic among male adolescents. As a consequence, late-life mortality is much higher for male (but not female) individuals who were around age 15 at the end of the famine (Horiuchi, 1983).

The first wave of the Spanish Influenza pandemic hit Germany in June 1918, the second one in the Fall and the third one in January 1919 (Witte, 2008). In Germany, about 150,000 individuals died in this period as a result of the disease (Vincent, 1985). This number is low when compared to the overall number of deaths that resulted from starvation, but it is still considerable. Because identification in our study relies on comparing outcomes of the descendants of adjacent first-generation cohorts, it is difficult to separate the effects of the famine from the effects of the influenza pandemic. However, evidence from Norway suggests that, for the most part, the Spanish Influenza was lethal only for individuals of ages 20-40, such that selective survival is not an issue for our cohorts of interest (Mamelund, 2003). Nevertheless, since the continuation of the blockade and the third wave of the Spanish influenza extended well into 1919, we conduct sensitivity checks that include the year 1919 in our famine period.

\section{Identification and Outcome Models}

We use common coefficient models and matching to identify the effect of SGP famine exposure of first generation (G1) ancestors on second (G2) and third generation (G3) individuals. We thus calculate a famine effect among G2 and G3 individuals with the same background and birth year, who differ with respect to exogenous first generation famineSGP exposure. Because, first generation famine-SGP exposure is a historical incident that is exogenous at the individual level, our approach allows us to identify the impact of having ancestors of a certain age during the famine on the second and third generation. ${ }^{12}$

\subsection{Famine exposure}

To investigate systematically how adult outcomes of G2 and G3 vary with first generation SGP exposure to the famine, we focus on individuals who have at least one ancestor born

\footnotetext{
${ }^{11}$ The number of occurrences of epidemic diseases such as typhoid, rabies, trichiniasis and dysentery stayed roughly constant in the population.

${ }^{12}$ Note that our measure of famine exposure is whether someone had reached a certain age by the time of the famine. This measure thus reflects the intention to treat (ITT) and not the actual treatment effect (TE). Our data do not contain information on whether a first generation individual actually went hungry during the famine (for a discussion of ITT and TE effects in famine studies see van den Berg et al., 2012). Recall however that the famine was widespread and more severe than other famines in Europe in the past 150 years.
} 
Figure 1: Birth rate, German empire

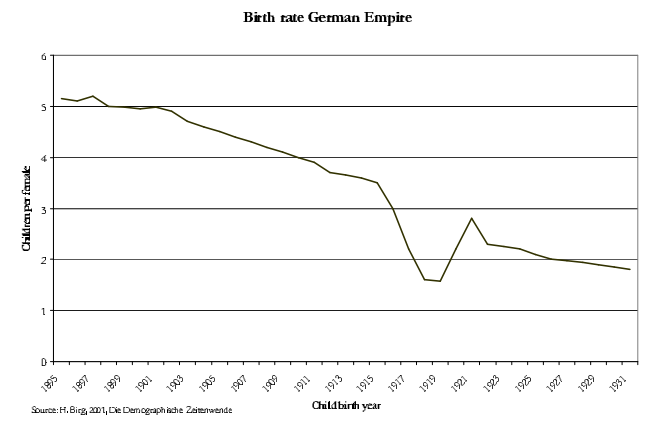

Source: H. Birg, 2001, Die Demographische Zeitenwende.

during the years 1902-1913. Note that male individuals in this cohort were too young to have been drafted and females were too young to have conceived a child during Word War I. Also, none were born during the war.

Table 2 displays the number of years the famine affected different birth cohorts of first generation individuals during their SGP, defining 1916-1918 as the famine period. Note that all first-generation individuals have been affected by the famine, but that exposure occurred at different ages. ${ }^{13}$ We thus identify the effect of being famine exposed during SGP as compared to being affected by the famine at a different point in time.

Our analysis relies on the assumption that there are no systematic differences in famine survival between individuals affected by the famine during the SGP and the control groups. Hence, we assume that children in their slow growth period were about equally likely to die from the famine than children that were slightly younger or older at the time. Historical sources seem to back this claim: death rates of children between the ages of one and five had risen by fifty percent during the famine, while for children from five to fifteen were only slightly higher $(55 \%)$ (Vincent, 1985). Selection into fertility would be a problem if parents from different social classes had been more or less likely to conceive children in the periods 1902-1903 (1902-1904) or 1910-1913 (1911-1913) than during the years 1904-1909 (1906-1910). Figure 1 however shows that for the time period of births we are analyzing (1901-1914), overall birth rates do not show any systematic pattern. Of course, it was impossible to anticipate the famine a decade earlier.

The exogenous shifter in nutrition, $Z \in\{0,1\}$, is defined as an indicator of whether G1 ancestors were SGP-exposed to the famine, i.e. of ages 8-10 (females) and of ages 9-12 (males) in 1916-1918. For G2, $Z$ is a $2 x 1$ vector with the first entry indicating whether the mother was affected by the famine during her SGP and the second indicating whether the

\footnotetext{
${ }^{13} \mathrm{~A}$ rare exception for a historical event where there is a control group which is largely unaffected is the Dutch Hunger Winter (see e.g. Scholte et al., 2012).
} 
Table 2: Number of years of famine exposure during the slow growth period, first generation males and females.

\begin{tabular}{|c|c|c|c|c|c|c|c|c|c|c|c|c|}
\hline Birth year & 1902 & 1903 & 1904 & 1905 & 1906 & 1907 & 1908 & 1909 & 1910 & 1911 & 1912 & 1913 \\
\hline Males & 0 & 0 & 1 & 2 & 3 & 3 & 2 & 1 & 0 & 0 & 0 & 0 \\
\hline Females & 0 & 0 & 0 & 0 & 1 & 2 & 3 & 2 & 1 & 0 & 0 & 0 \\
\hline Age during famine & $14-16$ & $13-15$ & $12-14$ & $11-13$ & $10-12$ & $9-11$ & $8-10$ & $7-9$ & $6-8$ & $5-7$ & $4-6$ & $3-5$ \\
\hline
\end{tabular}

father was affected during that same period. Following the same logic, for G3, $Z$ has four entries: whether paternal grandfather (PGF) was SGP famine affected, whether paternal grandmother (PGM) was SGP famine affected, whether maternal grandfather (MGF) was SGP famine affected and whether maternal grandmother (MGM) was SGP famine affected.

\subsection{Outcome models}

We estimate three different types of outcome models to account for the different distributional properties of the respective outcome variables: a duration model for individual mortality, a discrete choice probit model for the decision to obtain a higher secondary school degree and a linear regression model for the continuous outcomes height and mental health. In all models, $x$ denotes an individual-specific vector of observable characteristics, which always comprises some basic control variables and in some specifications an additional set of background controls. $f_{y}$ is a vector of birth year dummies for the respective generation that captures any variation that may be cohort or birth year specific.

\subsubsection{Duration model}

First, to estimate the impact of the famine on longevity of the second generation, we model the hazard of mortality at any given point in time as being composed of the baseline hazard and a systemic part. Following the standard biological literature on modeling mortality, the baseline hazard has the shape of a Gompertz distribution with ancillary parameter $\gamma$ :

$$
h(t)=\exp (\gamma t) \exp \left(\sum_{i=1}^{N} Z_{i}^{\prime} \delta+x_{i}^{\prime} \beta+f_{y}^{\prime} \eta\right) .
$$

Our sample is special in a sense that selection into the sample is conditional on ever having responded to a the household questionnaire. We thus account for left truncation by adjusting the likelihood for the fact that individuals only enter in adult life, using age at 
first interview as truncation point. ${ }^{14}$

\subsubsection{Probit model}

We model binary outcomes such as disability status or upper secondary schooling as a binary outcome latent index model with $Y_{i t}=1_{\left[Y_{i t}^{*}>0\right]}$, where $Y_{i t}^{*}$ denotes the latent continuous variable. The latent variable in turn is determined by famine exposure, birth year fixed effects and observable control variables. We assume a linear structure and additive separability in the error term:

$$
Y_{i}^{*}=Z_{i}^{\prime} \delta+x_{i}^{\prime} \beta+f_{y}^{\prime} \eta+\epsilon_{i t}
$$

The observed binary variable $Y_{i}$ is an indicator variable that is assumed to equal one if the latent variable crosses zero as a threshold $Y_{i}^{*}>0$. We estimate a probit model, assuming that $P\left(Y_{i t}=1 \mid x_{i}, f_{y}, Z_{i}\right)=\Phi\left(Z_{i}^{\prime} \delta+x_{i}^{\prime} \beta+f_{y}^{\prime} \eta\right)$ where $\Phi$ denotes the normal cdf.

\subsubsection{Linear regression model}

For continuous outcomes, we estimate the following linear model between outcomes $Y_{i t}$, famine effects and covariates for adult $\mathrm{i}$ born in year $\mathrm{t}$ :

$$
Y_{i}=Z_{i}^{\prime} \delta+x_{i}^{\prime} \beta+f_{y}^{\prime} \eta+\epsilon_{i t}
$$

again $x_{i}$ denotes a vector of control variables and the equation comprises a vector of own birth-year fixed effects $\left(f_{y}\right)$ to capture any variation that may be cohort or birth year specific.

\section{Data}

The German Socioeconomic Panel is a representative longitudinal survey data set. Since 1984, around 12,000 households, comprising more than 20,000 individuals, are followed over time. The sampling unit is the household, and all household members aged 17 or above participate in the survey. Individuals who leave the household to form a new household are kept in the sample, as are their new household members. At the age of 17, children of

\footnotetext{
${ }^{14}$ We conduct robustness checks where we introduce a frailty term $(\alpha)$ that enters the hazard function multiplicatively:

$$
h(t)=\alpha \mu_{0} .
$$

We find that the introduction of unobserved heterogeneity hardly affects the results.
} 
participating households become full-blown survey participants. Attrition from the panel is compensated by refreshment samples aimed at maintaining representativeness for the full population.

The survey participants are interviewed once a year. An average interview takes about 1.5 hours. The survey is a broad multi-purpose survey. It aims to obtain extensive information on socioeconomic outcomes, demographic conditions, living conditions, opinions, behavior, consumption, etc. of the respondents and their household. In certain waves of the survey, individuals are exposed to modules covering special topics such as health status, cognitive abilities, or family trees. In their respective first SOEP interviews, the adult respondents were asked about the birth years of their parents if the latter were not SOEP respondents themselves. In case a parent had died, the death year was also asked for.

\subsection{Sample}

The data design leads to a natural choice of what constitute the three generations in our analysis. The second generation (G2) are adult SOEP respondents. The first generation (G1) are their parents, while G3 are their children. This is the only choice that leads to a substantial number of G1 individuals who experience the 1916-1918 famine in their SGP. By relating their birth year to the famine period we infer whether they were exposed to the famine during their SGP or indeed during any other age interval.

The actual selection of the G1, G2, G3 sample is rather involved. First, we select all adult SOEP respondents as candidate G2 members whose parents are of German nationality and do not have a migration background. We then exclude candidate G2 members who reported unreasonable G1 birth years in a sense that their fathers (mothers) would have had the G2 individual before age 15 (15) or after age 70 (50). Similarly we exclude all candidate G3 members for whom the age differences between G2 and G3 individuals are unreasonably high or low. G1 members are then only selected if they have G2 children who are adult in at least one wave of the survey. Moreover, all G1 members need to be one of two G2 parents or one of four G3 grandparents of which at least one needs to be born in 1902-1913. In other words, we link all G2 individuals to their parents and all G3 individuals to their grandparents and only keep individuals in our G3-sample (G2-sample) if at least one grandparent (parent) is born in 1902-1913. If the latter condition is not satisfied or if the relevant years are missing for at least one grandparent (parent) then the candidate G3 (G2) member is excluded from the G3-sample (G2-sample). Similarly, if one of the candidate G2 members was born in 1902-1913 then the family is discarded.

As a result, our G3-sample (G2-sample) contains 2670 (6548) G1 individuals who were born in 1902-1913. In addition, 580 (855) and 1914 (873) G1 individuals are born before 
1902 and after 1913, respectively. The data contain 4138 G2 individuals and 1291 G3 individuals. ${ }^{15}$ See Table 3 for more details. ${ }^{16}$

As noted in Section 1, our study design faces a few potential limitations. Some of these are inevitable (but often ignored) in the study of transgenerational effects. Specifically, the study of three consecutive generations of a family requires that family members of the first two generations survive until reproductive ages and that they actually get children, and that the family members of the third generation survive until the moment that the outcome of interest can be observed. Moreover, the second generation individuals must have received the children in a relationship that was sufficiently stable to observe both partners in the same household. Further, the third generation individuals only enter the survey if they lived in the same household with their parents at some point after the household entered the study (most households entered in 1984). This explains why most of the third generation individuals in our sample were born after 1963 and are thus relatively young, and why the second generation individuals were on average relatively old when they had children. These conditions may be selective in that they relate to evolutionary fitness. In our observation window, the single largest peak in mortality occurs during and right after World War II. This would be a problem if World War II affected reproductive behavior in the SGP famine cohort differently than in adjacent cohorts. It is likely that many G1 individuals, although mostly older than 30 years of age during World War II, were drafted in that war. This holds true for both the treatment and the control group, such that there should be no systematic differences in battlefield exposure. Also, World War II occurred after most G1 individuals (whether in the SGP famine cohort or not) had obtained their first children and before the G2 individuals reached ages at which they were drafted. Nevertheless, we deal with the peak in mortality by including indicators for G2 birth years in the models we estimate.

A potential limitation compared to the design of the Överkalix studies is that the 19161918 famine was a single adverse event, so that exposure during the SGP is equivalent to birth in or around 1907 (specifically, for boys in the interval 1904-1909 and for girls in the interval 1906-1910, where the highest exposure during the SGP occurred in the middle of the intervals). This is not so much a sampling limitation as a limitation of the historical variation in SGP conditions. In the Överkalix studies, favorable and adverse years follow each other with a certain frequency. Our design would be flawed if 1907 and the years around it were special in the sense that the composition of newborns was systematically

\footnotetext{
${ }^{15}$ In addition we conduct robustness checks where we restrict our attention to only those G1 individuals who were born in 1902-1913. That is, we then focus only on G2 and G3 individuals if all their G1 ancestors were born in that period. This leaves us with much smaller sample sizes of 1232 G2-males and 1261 G2-females and of 178 G3-males and 137 G3-females, respectively.

${ }^{16}$ In the G3 generation sample we count 659 siblings who mostly have the same ancestors.
} 
different. However, macro-economic statistics of the years 1900-1910 do not suggest that this was the case. For example, the German economy grew at a rather steady rate until World War I. A similar potential problem could arise if the 1907 cohort was exposed to a cohort-specific shock later in life. In general, these concerns are dealt with by including a large number of indicators of secular changes in society and background controls. In addition, we point out that if the cohorts born in and around 1907 are selective in a way that is unrelated to the effects we are interested in then we would expect this to affect the results for each of the four grandparents. It is unlikely that the presence of an effect of the parental grandfather's SGP exposure is caused by a mechanism that is unrelated to the effects we are after if we do not find an effect of the maternal grandfather's SGP exposure.

An additional issue originates from the combination of the single adverse famine shock and the fact that the sampling starts with potential G2 members. The latter come from the cross-section of individuals alive at some point during the SOEP observation window. Because of the age composition of the population, this means that they were born on average in the late 1930s. Any G1 parent of such an individual who was exposed to the famine in his/her SGP can not have been a young father in the late 1930s (on average they were around 30 years old). This could affect the G2 upbringing. Moreover, epidemiological studies have shown a positive association between higher paternal age at birth and leukocyte telomere length in adulthood (see e.g. Kimura et al., 2008). The latter is known to be associated with beneficial health outcomes later in life such as a lower mortality rate. We address this issue in the same way as in the previous paragraph, by conditioning on indicators of secular trends and background control variables. Moreover, recall that among the G1 members who were not famine-exposed in their SGP we also observe many who received offspring in their thirties or after that.

Table 3: Sample size and ancestor famine affectedness.

\begin{tabular}{|c|c|c|c|c|c|c|c|c|}
\hline \multirow[b]{3}{*}{ Father famine in SGP } & \multicolumn{4}{|c|}{ Second generation } & \multicolumn{4}{|c|}{ Third generation } \\
\hline & \multicolumn{2}{|c|}{ Males } & \multicolumn{2}{|c|}{ Females } & \multicolumn{2}{|c|}{ Males } & \multicolumn{2}{|c|}{ Females } \\
\hline & 0.40 & $(0.49)$ & 0.42 & $(0.49)$ & . & $()$. & . & $()$. \\
\hline Mother famine in SGP & 0.35 & $(0.48)$ & 0.33 & $(0.47)$ & . & $()$. & . & $()$. \\
\hline PGF famine in SGP & . & $()$. & . & $()$. & 0.29 & $(0.45)$ & 0.35 & $(0.48)$ \\
\hline PGM famine in SGP & . & $()$. & . & $()$. & 0.23 & $(0.42)$ & 0.24 & $(0.43)$ \\
\hline MGF famine in SGP & . & $()$. & . & $()$. & 0.26 & $(0.44)$ & 0.22 & $(0.42)$ \\
\hline MGM famine in SGP & . & $()$. & . & $()$. & 0.19 & $(0.39)$ & 0.16 & $(0.37)$ \\
\hline Birth year & 1938.86 & $(6.36)$ & 1938.76 & $(6.63)$ & 1973.20 & $(7.85)$ & 1974.41 & $(7.15)$ \\
\hline $\mathrm{N}$ & 2061 & & 2077 & & 715 & & 576 & \\
\hline
\end{tabular}




\subsection{Outcome variables}

Our outcome measures $\left(Y_{i t}\right)$ are height, longevity, mental health and whether an individual has obtained an upper secondary school degree. In the SOEP, age at death can be obtained for individuals who have participated in the survey at least once and who dropped out of the survey because they died. The death year is provided by the SOEP in the socalled person-based metafile. Mental health and height measures are obtained using the most recent information from the biannual SOEP health module. Height is self-reported and mental health is measured by the Mental Component Summary Scale (MCS), one of the two sub-dimensions of the SF-12 questionnaire. The MCS is measured on a scale that ranges from 0 to 100 with mean 50 and standard deviation 10. It results from a factor analysis comprising the dimensions 'general mental health', 'emotional functioning', 'social functioning' and 'vitality' each measured on separate scales (for details see Andersen et al., 2007). We define whether an individual has obtained the German university or technical college entrance diploma (German "Abitur" or "Fachhochschulreife") using the international Comparative Analysis of Social Mobility in Industrial Nations (CASMIN) classification. Table 4 comprises summary statistics of all outcome variables. ${ }^{17}$

Table 4: Descriptive statistics: Age at death, height, mental health and schooling outcomes by sex and generation.

\begin{tabular}{|c|c|c|c|c|c|c|c|c|}
\hline \multirow{3}{*}{$\begin{array}{l}\text { Variables } \\
\text { Age at death }\end{array}$} & \multicolumn{4}{|c|}{ Second generation } & \multicolumn{4}{|c|}{ Third generation } \\
\hline & \multicolumn{2}{|c|}{ Males } & \multicolumn{2}{|c|}{ Females } & \multicolumn{2}{|c|}{ Males } & \multicolumn{2}{|c|}{ Females } \\
\hline & 71.91 & $(6.35)$ & 72.90 & $(6.24)$ & & & & \\
\hline Height & 175.52 & $(6.63)$ & 163.72 & $(6.03)$ & 180.51 & $(7.05)$ & 167.76 & $(6.06)$ \\
\hline Mental health & 52.50 & $(9.77)$ & 50.45 & (10.69) & 49.44 & $(9.18)$ & 47.57 & $(9.98)$ \\
\hline Upper secondary school degree & 0.36 & $(0.48)$ & 0.19 & $(0.39)$ & 0.49 & $(0.50)$ & 0.52 & $(0.50)$ \\
\hline $\mathrm{N}$ & 2061 & & 2077 & & 715 & & 576 & \\
\hline
\end{tabular}

\subsection{Control variables}

We define two sets of control variables: basic control variables and background control variables. Basic control variables comprise all variables that account for any bias that may arise because famine-affected G1 individuals (and their offspring) are (may be) born in different years than the corresponding control group members. Most importantly, in accordance with research showing that wars and famines can have lasting scars on those

\footnotetext{
${ }^{17}$ We do not consider wages, because our data are a cross section of individuals who are sampled at different points in their lives, which makes the computation and comparison of (permanent) income problematic.
} 
Figure 2: GDP per capita and population size, German Empire

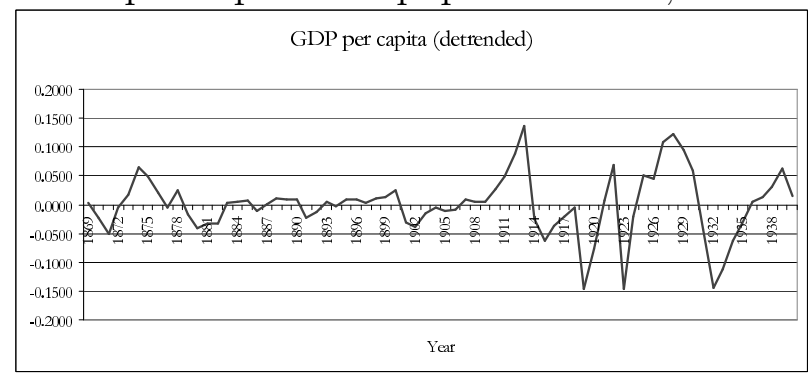

Notes: GDP per capita (logarithm) is measured in 1990 International Geary-Khamis dollars. GDP was detrended using the Hodrick-Prescott-Filter $(\lambda=100)$.

Source: A. Maddison (2006). The World Economy: Historical Statistics, OECD Development Centre, Paris 2006.

individuals who were born at that time (see e.g. Lumey et al., 2011), we are including indicator variables for whether G2 individuals were born during World War I and for whether G2 individuals were born during World War II. Note however that our sample comprises rather few of those individuals (68 G1 and 140 G2). Second, we are controlling for individual birth year fixed effects to capture cohort or birth year specific variation in outcomes. Last, we include detrended GDP per capita during the year of birth of G1 (see Figure 2) in line with a strand of literature which demonstrates that economic and health conditions at birth and during infancy can have long-run mortality and height effects. (For the effect of business cycle variation on outcomes see e.g. van den Berg et al., 2011, Woitek, 2003 and Sunder and Woitek, 2005.)

We include background variables as additional covariates in some specifications to detect behavioral, non-biological pathways. One of the potentially most important pathways goes through parental education, reflecting parental cognitive ability, parenting skill, social class and family earnings potential all of which are essential for health and schooling outcomes. We define parental education dummies for different educational degrees in Germany. In addition, we include the number of siblings, as a proxy for parental resources. Descriptive statistics of all included background variables can be found in Table 5 .

\section{Empirical results}

The results are discussed in two stages. First, in Subsection 6.1 we discuss how grandparental SGP famine exposure affects outcomes in the third generation. These are the findings that most reliably allow us to draw conclusions about epigenetic pathways and that can be connected directly to the main findings in the Överkalix studies. We investigate 
Table 5: Descriptive statistics: Background control variables.

\begin{tabular}{lllll}
\hline & \multicolumn{2}{l}{ Second generation } & \multicolumn{2}{l}{ Third generation } \\
\hline Father upper secondary school & 0.10 & $(0.30)$ & 0.33 & $(0.47)$ \\
Father intermediate school & 0.09 & $(0.28)$ & 0.17 & $(0.37)$ \\
Mother upper secondary school & 0.03 & $(0.17)$ & 0.21 & $(0.41)$ \\
Mother intermediate school & 0.11 & $(0.31)$ & 0.26 & $(0.44)$ \\
Number of brothers & 0.99 & $(1.06)$ & 0.72 & $(0.77)$ \\
Number of sisters & 0.99 & $(1.10)$ & 0.77 & $(0.87)$ \\
\hline N & 4138 & & & \\
\hline Source: German Socioeconomic Panel (SOEP). & & & \\
Own calculations. &
\end{tabular}

how the results change if we move from controlling only for a basic set of variables to controlling for additional background variables, which potentially account for non-biological channels. We also conduct robustness checks where we vary famine intensity and period, e.g. by excluding individuals who experienced the famine for only one year and by extending the famine period to 1919. If famine exposure has a causal effect on outcomes, we expect this effect to become larger and more significant if individuals with weak famine exposure are excluded from the analysis. Last, we restrict the sample to individuals for whom all G1-ancestors were born during the period 1902-1913.

Second, in Subsection 6.2 we discuss the results of parental SGP famine exposure on the second generation, keeping in mind that these findings may be driven by a range of mechanisms including epigenetic mechanisms but also direct behavioral or environmental processes. Nevertheless, we expect these results to be informative about how any potential effect transmits from the first to the third generation.

\subsection{Third generation}

The coefficients in Table 6 display the effect sizes of grandparental SGP-famine exposure on height, mental health and schooling, conditional on the basic set of control variables and on the combined set of basic and background controls. Since epigenetic inheritance may be sex specific, we perform all analyzes separately for males (left panel) and females (right panel) (Pembrey et al., 2006). We report p-values that correspond to robust standard errors clustered at the household level, because siblings share genes, environment, and history of ancestral famine exposure. Note that there are four ancestors who have potentially been affected by the famine during their SGP: the paternal grandfather, the paternal grandmother, the maternal grandfather and the maternal grandmother. If our results are driven by transgenerational epigenetic mechanisms, we should expect positive and significant effects on G3 height, schooling and mental health. Of particular interest is 
whether we find positive and significant coefficients for paternal grandfather exposure for males and for maternal grandmother exposure for females.

The coefficients displayed in rows 1 and 7 of Table 6 do indeed indicate positive effects on height along the male and female lines, but the effect sizes are small and insignificant. Similarly, the effects on schooling are close to zero. Hence, for these two outcomes we do not find evidence in support of epigenetic transmission mechanisms. For mental health, the case is different: in line with the findings by Kaati et al. (2007) our results displayed in Columns 3 and 9 of Table 6 indicate that paternal grandfather SGP exposure does indeed have a positive effect on mental health of grandsons, while maternal grandmother SGP exposure positively affects granddaughters' mental well-being. Thus, as predicted by the theory, mental health is positively affected by a nutritional shock to the first generation, and the effect transmits along the male and female line, respectively. The right columns in Table 6 display coefficients for models with additional controls for parental education and sibship size. If our findings were driven by changing opportunities, fertility or first generation cognitive ability, we would expect changes to our coefficients' size and significance after the introduction of these additional background variables. We conduct a likelihood ratio test for the improvement in model fit due to the additional variables and find that controlling for parental background improves the fit to the data, but does not reduce the size and significance of mental health coefficients. The results indicate that having a paternal grandfather or a maternal grandmother who has been affected by a famine during SGP improves mental health by about 1.6 points, or $16 \%$ of a standard deviation, for males and by about 2.2 points, or $22 \%$ of a standard deviation, for females.

Table 7 displays the coefficients of the robustness check where the left column shows the famine effect of at least two years of famine exposure, excluding individuals who experienced the famine for only one year of their SGP from the sample, and the right column shows the SGP famine effect with the extended famine period. We expect coefficients to increase if only the more highly affected individuals are included in the analysis. We find that point estimates for mental health mostly increase if we only include the most highly affected individuals. If the paternal grandfather is affected by the famine during his SGP, grandsons' mental health now tends to be $21 \%$ of a standard deviation higher and if the maternal grandmother is affected. The increase in mental health for granddaughters is only slightly smaller than in the previous specification, but now turns insignificant. Effects remain large and significant when the famine period is extended to the year 1919. 


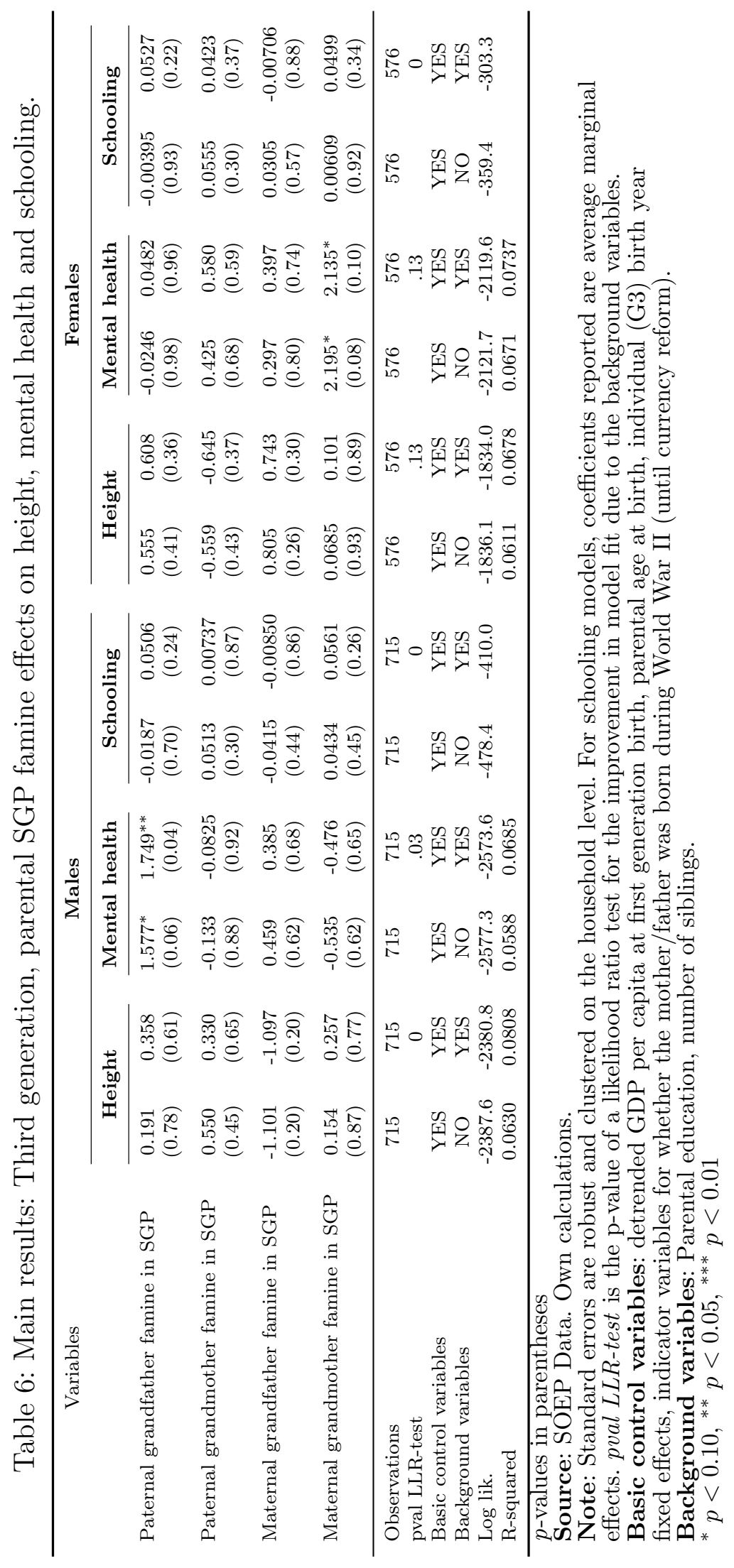




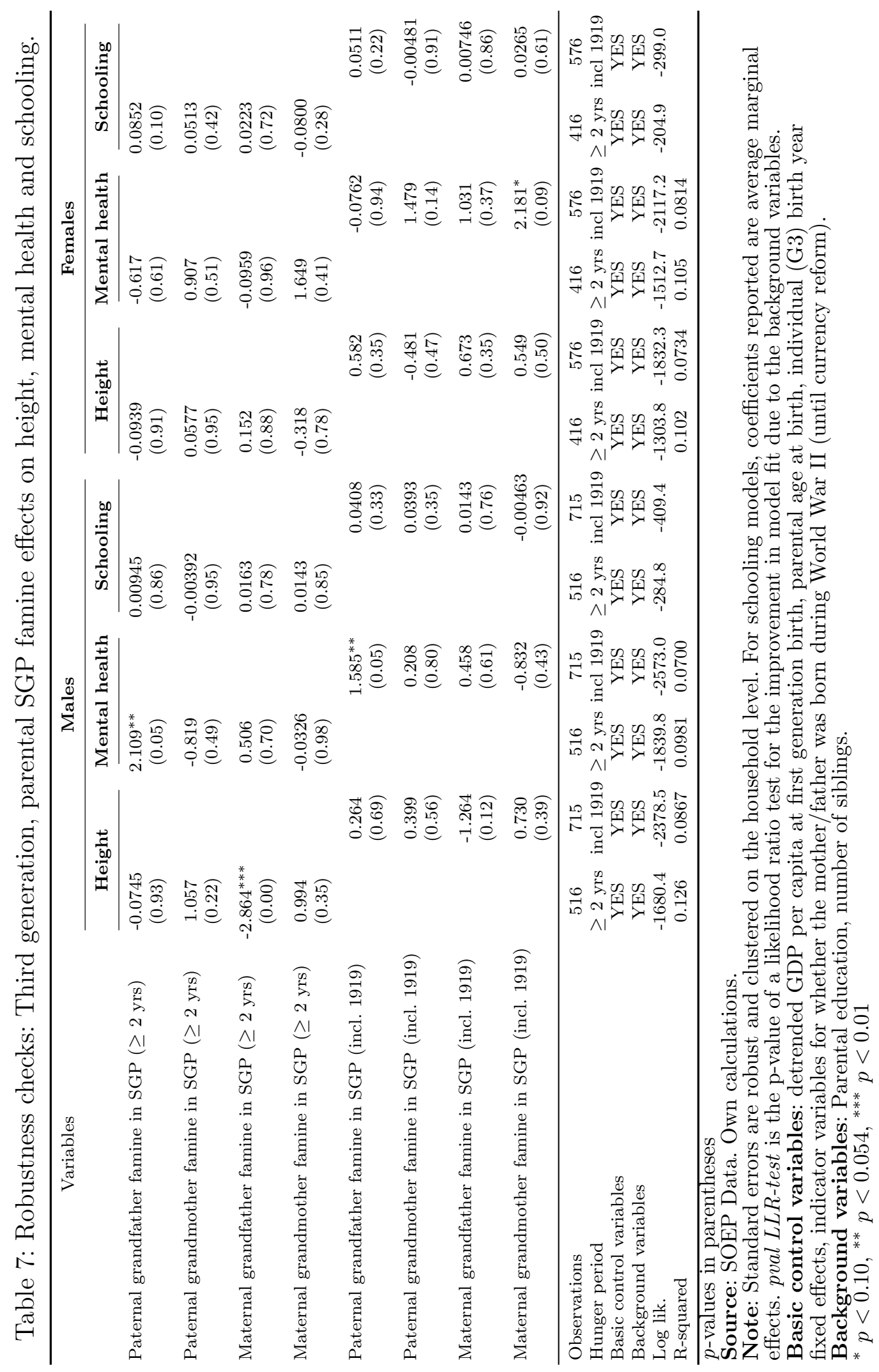


If we restrict the sample to only those individuals with all G1-ancestors born during 1902-1913 (results not displayed), we find positive height effects if the paternal grandfather was exposed for both males and females. Moreover, we find highly significant positive mental health effects for females whose maternal grandmothers were exposed but no significant effects for males whose paternal grandfathers were exposed. A problem with this sample is, however, that it is rather small and that almost all individuals in it have at least one first generation ancestor who was exposed to the famine during the SGP. Consequently, the control group of completely unexposed individuals becomes tiny (2 males and 6 females) and the result may be affected by that. ${ }^{18}$

\subsection{Second generation}

The analysis so far has focused on the third generation, where any findings most reliably point towards transgenerational epigenetic effects. For two reasons, we also present results for the second generation. First of all, the fact that about $10 \%$ of the G2 individuals have died enables us to examine mortality effects, albeit to a limited extent. Second, for the interpretation of the G3 results it is interesting to examine whether the effects on mental health are also present in the second generation.

Table 8 displays the main results for G2 and Table 9 contains the same robustness checks as for G3 discussed above. Overall, we do not find robust effects on G2 mortality or height if a parent has been exposed during the famine during SGP. If at all, males tend to be slightly shorter if the mother, and slightly taller if the father has been affected by the famine. Furthermore, the coefficient on parental SGP famine exposure on schooling is negative and significant in some specifications for males. We suspect that the negative schooling effects of paternal famine exposure on male individuals are nonbiological effects that come about, because fathers who experienced the famine during adolescence received less rigorous training. This presumption is supported by the fact that the effect becomes insignificant in Column 7 of Table 9 where the less severely affected fathers are excluded from the analysis. Turning to second generation mental health, we neither find supportive evidence that paternal SGP famine exposure raises son's mental health nor that maternal SGP famine exposure has positive mental health effects for their daughters. ${ }^{19}$

\footnotetext{
${ }^{18}$ Our results are robust for varying sets of background control variables. Additional variables we included to test for robustness comprise age at the time of measurement, population growth, indicator variables for whether G1 individuals were born before 1902 or after 1913 as well as parental (G1 and G2) age at the birth of the children. For G3, the results also robust with respect to the inclusion of parental (G2) birth year fixed effects that capture business cycle fluctuations and variation in the probability for an individual to be part of the sample.

${ }^{19}$ Similarly, if we restrict the sample to only those G2 individuals for whom both parents were born during 1902-1913, we do not find any significant mental health effects.
} 


\subsection{Discussion}

The above findings hint towards the transgenerational epigenetic transmission of effects triggered by a reduction in food access during the ancestors' slow growth period: if the paternal grandfather is affected by a nutritional shock during his SGP, then this improves mental health among the third-generation male offspring. Similarly, if the maternal grandmother is affected by a nutritional shock during her SGP, this leads to an improvement in mental health among the third-generation female offspring. In this subsection we perform some additional analyses to shed light on the plausibility of the presence of an epigenetic pathway.

First, to assess whether our findings are indeed driven by a food shortage in SGP, we exclude all individuals from the analysis who have only been affected by the famine for a single year during their SGP. We find that most second generation results become weaker, but that the positive effect of paternal grandfather SGP exposure on male mental health and the positive effect of maternal grandmother SGP exposure on female mental health remain strong and significant. We interpret this as supportive for the evidence that the pathway starts with a nutritional shortage in the SGP.

Concerning the channels through which the transgenerational effect operates, we cannot be certain that our estimated effects are of epigenetic origin, because our data do not contain methylation patterns. It is interesting to note however, that the findings are to some extent similar to those in the above-described series of papers on the Överkalix data, which conclude that their findings are likely driven by epigenetic mechanisms. All third generation mental health effects appear along sex-specific lines and they are most significant and robust along the male line, which might be reasonable because during the SGP the sperm is still in development. Nevertheless, behavioral mechanisms are another possible explanation for our findings. The experience of economic hardship around the age of 10 has been found to increase resilience and psychological strength (Elder, 1999) and may therefore have positive mental health effects. However, it is not evident why behavioral mechanisms should work exclusively along sex-specific lines. Moreover, if third generation mental health was elevated due to an increase in first generation resilience and psychological strength, we would expect the effect to transmit to the third generation via elevated mental health levels among the second generation. Instead all mental health coefficients are insignificant for the second generation. From this we conclude that the mental health effects we find for the third generation are more likely biological in origin and plausibly the result of epigenetic transmission.

The results on the G3 educational outcome may be affected by causal effects of G1's level of education on G3's level of education. Evidence of positive associations between G3 and G1 levels of education, controlling for G2 levels of education, is provided by Lindahl et 
al. (2013), using multigenerational data from Sweden. In our setting, it is conceivable that SGP famine exposure has a negative effect on the highest attained level of education of G1. This by itself could then generate a negative effect of G1's SGP famine exposure on G3's level of education. Such a pathway runs opposite to the epigenetic pathway that we focus on. This may explain our empirical finding that the net over-all effect is not significantly different from zero.

In fact, the data allow us to investigate this in some more depth, since they include G1's highest realized level of education. First, we examine whether G1 SGP famine exposure has a negative impact on G1 education. Table 10 presents average marginal effects from a probit analysis. It turns out that the effects are negative for males but not for females. The average effects on male upper secondary and secondary education amount each to a two percentage point reduction. In relative terms, this is quite considerable (around 20 percent), since the share of individuals with upper secondary and secondary education for these cohorts is around $10 \%$ each.

We proceed by investigating whether adding G3's realized education levels to our preferred specification impacts the mental health results displayed in 6. Table 11 displays the mental health results for G3 if we do not only account for parental (G2) but also for grandparental (G1) education. The results indicate that the SGP famine effect for males becomes stronger and more significant while for females it becomes less significant. That we do not find a major change in the results for females is not very surprising given that the realized level of education of G1 females was not affected by the famine in the first place. Conversely, controlling for G1's level of education reinforces the mental health effect for males. ${ }^{20}$ Another striking result is that paternal grandfather upper secondary education seems to affect male mental health while maternal grandmother secondary education seems to affect female mental health. This result suggests that both investments and shocks on the first generation affect mental health outcomes of the third generation and that the effect operates along sex-specific lines.

\section{Conclusion}

This paper investigates how a reduction in food supply due to the German World War I famine of 1916-1918 affects descendants of the second and third generation. A wellknown line of literature finds that low food availability during the slow growth period of male individuals positively affects health outcomes of subsequent generations. The studies involved argue that such effects are potentially triggered by methylation of epigenetic marks

\footnotetext{
${ }^{20}$ The estimated G1 SGP famine effects on G3 height and education hardly change if G1 education variables are included in the main specification.
} 
in the sperm, with methyl tags being transmitted to subsequent generations via epigenetic imprinting.

We find that paternal grandfather SGP-famine exposure is associated with higher mental health of third generation sons, while maternal grandmother SGP-famine exposure has a positive effect on her granddaughters' mental health. We conclude that these thirdgeneration mental health effects are likely to be causally related to a nutritional shortage during the SGP. The estimated effects are larger if famine exposure is redefined such that only the most severely affected individuals are included. Furthermore, the analyses indicate that it is implausible that the results are driven by behavioral mechanisms. For example, mental health effects are largely absent among the second generation. They take place along sex-specific lines and are stronger for males than for females. We conclude that it is likely that the results are driven by epigenetic imprinting.

Interestingly, mental health is among the most responsive adult health outcomes as a function of nutritional conditions in utero, according to the literature on famine exposure (see the survey in Lumey, Stein and Susser, 2011). This effect should not be confounded with the effect detected in our study. The latter is driven by nutritional conditions in the slow growth period, and it works on subsequent generations. Nevertheless, the results provide a further confirmation that adult mental health is affected by past nutritional shocks within the family.

The mental health results validate findings in the studies based on the Överkalix data. Yet, as an external validation of the studies based on those data, the present study provides mixed evidence. This is to some extent because the sets of observed third-generation outcome variables do not fully overlap. Notably, we are not able to use mortality and cardiovascular diseases as G3 outcome variables. For various reasons outlined in the paper, we may expect effects on mental health to be in line with effects on those outcome variables. However, note that we do not find strong evidence for male-line effects on G2 mortality or on G3 adult height as a proxy of mortality.

Research on transgenerational famine effects and epigenetic inheritance is only starting. Further validation studies are needed that provide evidence on how nutritional shocks transmit across generations, preferably including evidence on methylation changes. The present study may therefore motivate the construction or usage of data sets that contain elaborate retrospective information on nutritional shocks during childhood and adolescence, as well as methylation patterns and health outcomes for several generations. 


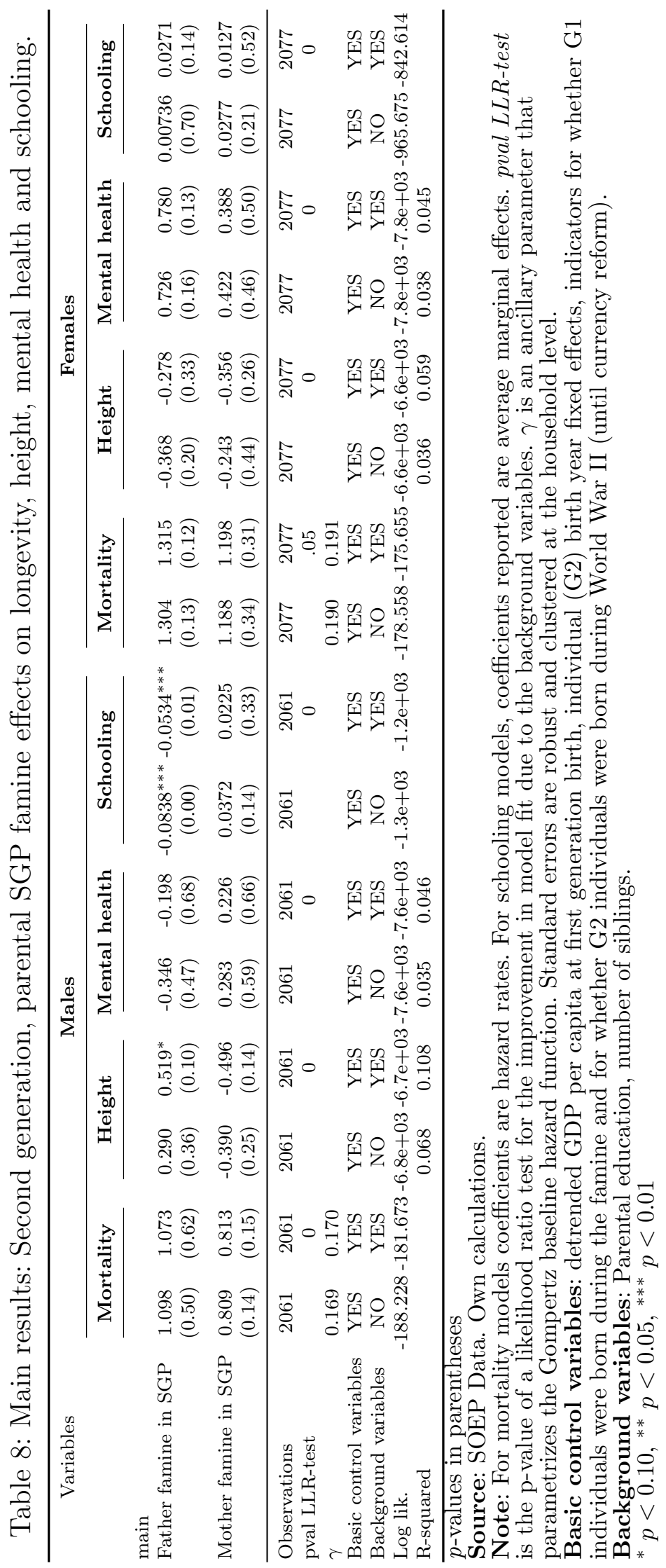




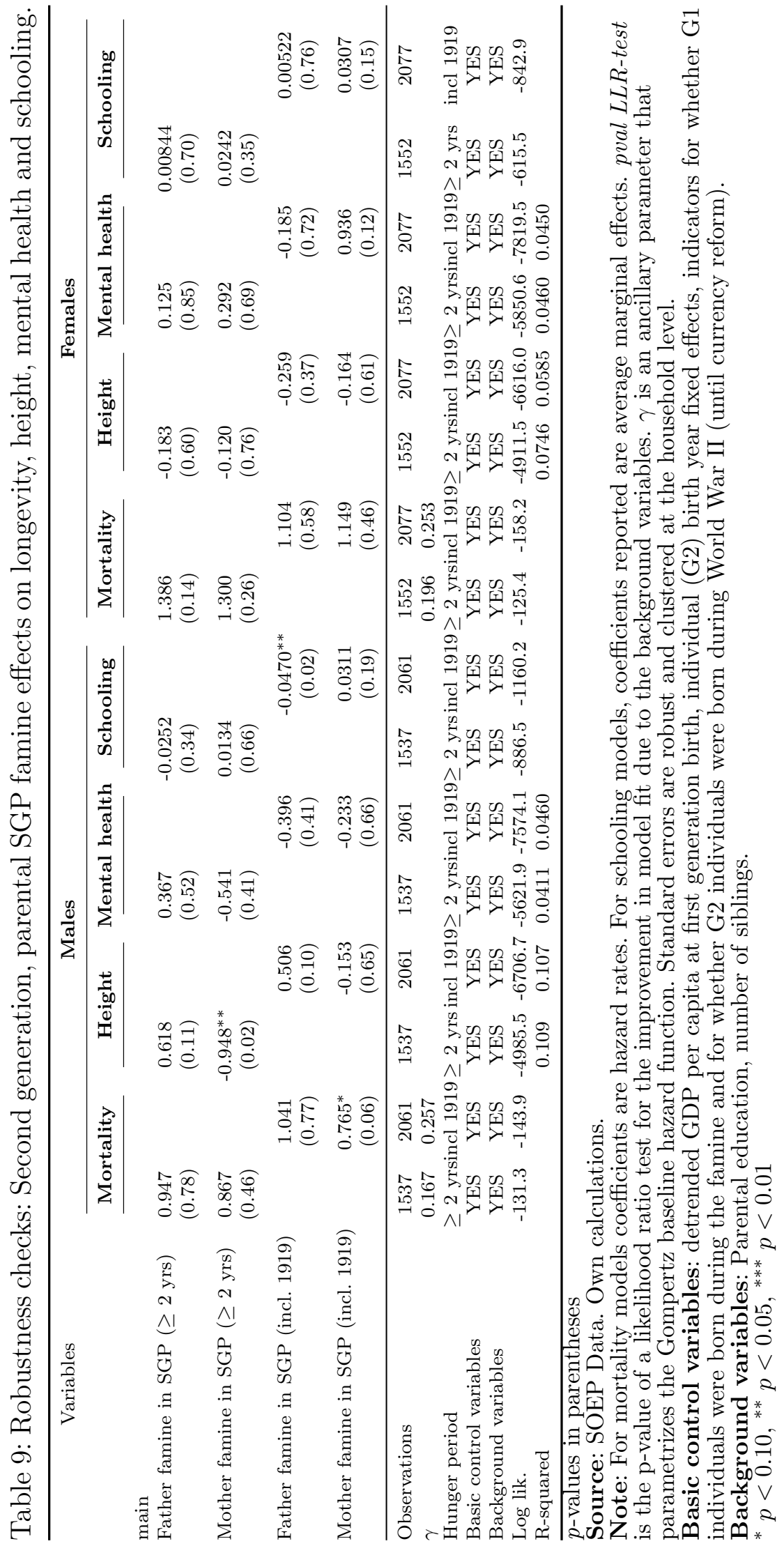


Table 10: Famine effect on first-generation education outcomes.

\begin{tabular}{|c|c|c|c|c|}
\hline \multirow[t]{2}{*}{ Variables } & \multicolumn{2}{|c|}{ G1 male } & \multicolumn{2}{|c|}{ G1 female } \\
\hline & Upper sec & Secondary & Upper sec & Secondary \\
\hline G1 male SGP famine exposure & $\begin{array}{c}-0.0240^{* * *} \\
(0.01)\end{array}$ & $\begin{array}{c}-0.0176^{* *} \\
(0.05)\end{array}$ & & \\
\hline G1 female SGP famine exposure & & & $\begin{array}{c}0.00567 \\
(0.36)\end{array}$ & $\begin{array}{c}0.00942 \\
(0.37)\end{array}$ \\
\hline Observations & 4138 & 4138 & 4138 & 4138 \\
\hline Birth year trend & YES & YES & YES & YES \\
\hline Log likelihood & -1334.9 & -1213.9 & -572.9 & -1399.3 \\
\hline Pseudo R-squared & 0.00473 & 0.00162 & 0.00838 & 0.00335 \\
\hline
\end{tabular}

$p$-values in parentheses

Source: SOEP Data. Own calculations.

Note: Table displays average marginal effects.

Standard errors are robust and clustered on the household level. Upper sec and Secondary refer to upper secondary school education and secondary school education

respectively (the base being lower secondary school education).

${ }^{*} p<0.10,{ }^{* *} p<0.05,{ }^{* * *} p<0.01$ 
Table 11: Effects of first-generation SGP famine and first-generation education on third-generation mental health outcomes.

\begin{tabular}{|c|c|c|c|c|}
\hline \multirow[t]{2}{*}{ Variables } & \multicolumn{2}{|c|}{ Males } & \multicolumn{2}{|c|}{ Females } \\
\hline & \multicolumn{4}{|c|}{ Mental health } \\
\hline Paternal grandfather famine in SGP & $\begin{array}{c}1.647^{* *} \\
(0.04)\end{array}$ & $\begin{array}{c}1.801^{* *} \\
(0.03)\end{array}$ & $\begin{array}{c}0.0876 \\
(0.93)\end{array}$ & $\begin{array}{c}0.0996 \\
(0.92)\end{array}$ \\
\hline Paternal grandmother famine in SGP & $\begin{array}{r}-0.197 \\
(0.82)\end{array}$ & $\begin{array}{c}-0.148 \\
(0.86)\end{array}$ & $\begin{array}{l}0.430 \\
(0.68)\end{array}$ & $\begin{array}{l}0.611 \\
(0.56)\end{array}$ \\
\hline Maternal grandfather famine in SGP & $\begin{array}{l}0.449 \\
(0.63)\end{array}$ & $\begin{array}{l}0.377 \\
(0.69)\end{array}$ & $\begin{array}{l}0.525 \\
(0.65)\end{array}$ & $\begin{array}{l}0.690 \\
(0.56)\end{array}$ \\
\hline Maternal grandmother famine in SGP & $\begin{array}{c}-0.703 \\
(0.52)\end{array}$ & $\begin{array}{c}-0.636 \\
(0.55)\end{array}$ & $\begin{array}{l}1.807 \\
(0.15)\end{array}$ & $\begin{array}{l}1.693 \\
(0.18)\end{array}$ \\
\hline Paternal grandfather upper secondary school & $\begin{array}{c}3.631^{* *} \\
(0.01)\end{array}$ & $\begin{array}{c}3.526^{* *} \\
(0.01)\end{array}$ & $\begin{array}{c}-0.195 \\
(0.93)\end{array}$ & $\begin{array}{c}-0.258 \\
(0.91)\end{array}$ \\
\hline Maternal grandfather upper secondary school & $\begin{array}{r}-1.797 \\
(0.27)\end{array}$ & $\begin{array}{c}-1.733 \\
(0.28)\end{array}$ & $\begin{array}{c}-1.421 \\
(0.38)\end{array}$ & $\begin{array}{r}-1.287 \\
(0.44)\end{array}$ \\
\hline Paternal grandmother upper secondary school & $\begin{array}{c}-1.804 \\
(0.35)\end{array}$ & $\begin{array}{r}-1.837 \\
(0.33)\end{array}$ & $\begin{array}{l}3.178 \\
(0.27)\end{array}$ & $\begin{array}{c}3.101 \\
(0.30)\end{array}$ \\
\hline Maternal grandmother upper secondary school & $\begin{array}{l}1.442 \\
(0.55)\end{array}$ & $\begin{array}{l}2.022 \\
(0.41)\end{array}$ & $\begin{array}{c}-5.272^{*} \\
(0.10)\end{array}$ & $\begin{array}{c}-5.095 \\
(0.11)\end{array}$ \\
\hline Paternal grandfather secondary school & $\begin{array}{c}-0.0867 \\
(0.95)\end{array}$ & $\begin{array}{c}0.00125 \\
(1.00)\end{array}$ & $\begin{array}{l}1.908 \\
(0.23)\end{array}$ & $\begin{array}{l}2.125 \\
(0.18)\end{array}$ \\
\hline Paternal grandmother secondary school & $\begin{array}{r}-1.147 \\
(0.44)\end{array}$ & $\begin{array}{c}-1.463 \\
(0.33)\end{array}$ & $\begin{array}{r}-0.817 \\
(0.63)\end{array}$ & $\begin{array}{c}-0.564 \\
(0.74)\end{array}$ \\
\hline Maternal grandfather secondary school & $\begin{array}{c}-0.140 \\
(0.91)\end{array}$ & $\begin{array}{c}0.0142 \\
(0.99)\end{array}$ & $\begin{array}{l}0.582 \\
(0.72)\end{array}$ & $\begin{array}{l}0.843 \\
(0.62)\end{array}$ \\
\hline Maternal grandmother secondary school & $\begin{array}{c}-0.0805 \\
(0.95)\end{array}$ & $\begin{array}{l}0.581 \\
(0.66)\end{array}$ & $\begin{array}{c}4.303^{* * *} \\
(0.00)\end{array}$ & $\begin{array}{c}4.291^{* * *} \\
(0.00)\end{array}$ \\
\hline Observations & 715 & 715 & 576 & 576 \\
\hline Basic control variables & YES & YES & YES & YES \\
\hline Background variables & NO & YES & NO & YES \\
\hline Log lik. & -2573.5 & -2569.9 & -2114.4 & -2112.6 \\
\hline R-squared & 0.0687 & 0.0781 & 0.0904 & 0.0960 \\
\hline
\end{tabular}

$p$-values in parentheses

Source: SOEP Data. Own calculations.

Note: Standard errors are robust and clustered on the household level.

Basic control variables: detrended GDP p.c. at first generation birth, parental age at birth, individual (G3) birth year fixed effects, indicators for mother/father born during World War II (until currency reform).

Background variables: Parental education, number of siblings.

${ }^{*} p<0.10,{ }^{* *} p<0.05,{ }^{* * *} p<0.01$ 


\section{References}

Andersen, H., Mühlbacher, A., Nübling, M., Schupp, J., and Wagner, G. (2007). Computation of standard values for physical and mental health scale scores using the SOEP version of SF-12v2. Schmollers Jahrbuch, 127(1): 171-182.

Baten, J., Dorothee C., and Voth, H.-J. (forthcoming). Poor, hungry and stupid: numeracy and the impact of high food prices in industrializing Britain, 1780-1850. Review of Economics and Statistics.

Birg, H. (2001). Die demographische Zeitenwende: der Bevölkerungsrckgang in Deutschland und Europa (Vol. 1426). CH Beck.

Blum, M. (2011). Government decisions before and during the First World War and the living standards in Germany during a drastic natural experiment. Explorations in Economic History, 48(4): 556-567.

Bygren, L., Kaati, G., and Edvinsson, S. (2001). Longevity determined by paternal ancestors nutrition during their slow growth period. Acta Biotheoretica, 49(1): 53-59.

Cooney, C. A. (2006). Germ cells carry the epigenetic benefits of grandmother's diet. Proceedings of the National Academy of Sciences, 103(46): 17071-17072.

Doblhammer, G., van den Berg, G. J. and Fritze, T. (2013). Economic conditions at the time of birth and cognitive abilities late in life: evidence from ten European countries. PLoS ONE, 8(9), e74915.

Elder, G. (1999). Children of the Great Depression: Social Change in Life Experience. Westview Press.

Farooq, A. (2010). Tales of adversity. Nature, 468(7327): 20.

Fraga, M. F., Ballestar, E., Paz, M. F., Ropero, S., Setien, F., Ballestar, M. L. et al. (2005). Epigenetic differences arise during the lifetime of monozygotic twins. Proceedings of the National Academy of Sciences of the United States of America, 102(30): 10604-10609.

Francis, R. C. (2011). Epigenetics: The ultimate mystery of inheritance. WW Norton.

Gasser, T. (1996). Development of fat tissue and body mass index from infancy to adulthood. Pediatric Nephrology, 10(3): 340-342.

Gasser, T., Ziegler, P., Largo, R. H., Molinari, L., and Prader, A. (1994). A longitudinal study of lean and fat areas at the arm. Annals of Human Biology, 21(4): 303-314.

Gräff, J. and Mansuy, I. M. (2008). Epigenetic codes in cognition and behaviour. Behavioural Brain Research, 192(1): 70-87. 
Grossniklaus, U., Kelly, B., Ferguson-Smith, A. C., Pembrey, M. and Lindquist, S. (2013). Transgenerational epigenetic inheritance: how important is it? Nature Reviews Genetics, 14(3): 228-235.

Harper, L. V. (2005). Epigenetic inheritance and the intergenerational transfer of experience. Psychological Bulletin, 131(3): 340-360.

Heijmans, B. T., Tobi, E. W., Stein, A. D., Putter, H., Blauw, G. J., Susser, E. et al. (2008). Persistent epigenetic differences associated with prenatal exposure to famine in humans. Proceedings of the National Academy of Sciences, 105(44): 17046-17049.

Hochberg, Z., Feil, R., Constancia, M., Fraga, M., Junien, C., Carel, J.-C. et al. (2011). Child health, developmental plasticity, and epigenetic programming. Endocrine Reviews, 32(2): 159-224.

Horiuchi S. (1983). The long-term impact of war on mortality: old-age mortality of the First World War survivors in the Federal Republic of Germany. Population Bulletin UN, 15: 80-92.

Huber, D. R. and Fogel, E. M. (1920). Food conditions and agricultural production. The Annals of the American Academy of Political and Social Science, 92(1): 131-136.

Huegel, A. (2003). Kriegsernährungswirtschaft Deutschlands während des Ersten und Zweiten Weltkrieges im Vergleich. Hartung-Gorre.

Jones, P. A., and Baylin, S. B. (2002). The fundamental role of epigenetic events in cancer. Nature Reviews Genetics, 3(6): 415-428.

Kaati, G. (2010). Case studies on epigenetic inheritance, in: A. Haslberger and S. Gressler, eds., Epigenetics and Human Health: Linking Hereditary, Environmental and Nutritional Aspects. John Wiley \& Sons.

Kaati, G., Bygren, L. O., and Edvinsson, S. (2002). Cardiovascular and diabetes mortality determined by nutrition during parents' and grandparents' slow growth period. European Journal of Human Genetics, 10(11): 682-688.

Kaati, G., Bygren, L. O., Pembrey, M., and Sjöström, M. (2007). Transgenerational response to nutrition, early life circumstances and longevity. European Journal of Human Genetics, 15(7): 784-790.

Kimura, M., Cherkas, L. F., Kato, B. S., Demissie, S., Hjelmborg, J. B., Brimacombe, M. et al. (2008). Offspring's leukocyte telomere length, paternal age, and telomere elongation in sperm. PLOS Genetics, 4(2): e37.

Klein, F. (1968). Deutschland im ersten Weltkrieg. Leipziger Universitätsverlag. 
Kuzawa, C. W. and Thayer, Z. M. (2011). Timescales of human adaptation: the role of epigenetic processes. Epigenomics, 3(2): 221-234.

Lindahl, M., Palme, M., Sandgren Massih, S., and Sjögren, A. (2013), Dynastic capital and long-term intergenerational persistence of earnings and educational attainment. Working paper, Stockholm University.

Lindeboom, M., Portrait, F. and van den Berg, G. J. (2010). Long-run effects on longevity of a nutritional shock early in life: The Dutch Potato famine of 18461847. Journal of Health Economics, 29(5): 617-629.

Low, F. M., Gluckman, P. D., and Hanson, M. A. (2012). Developmental plasticity, epigenetics and human health. Evolutionary Biology, 39(4): 650-665.

Lumey L. H., A. D. Stein, and Susser, E. (2011). Prenatal famine and adult health. Annual Review of Public Health, 32: 237-262.

Lundborg, P. and Stenberg, A. (2010). Nature, nurture and socioeconomic policy What can we learn from molecular genetics? Economics \& Human Biology, 8(3): 320-330.

Mamelund, S. E. (2003). Effects of the Spanish influenza pandemic of 1918-19 on later life mortality of Norwegian cohorts born about 1900. Research Memorandum, University of Oslo.

Marshall, W. and Tanner, J. (1968). Growth and physiological development during adolescence. Annual Review of Medicine, 19(1): 283-300.

Masterpasqua, F. (2009). Psychology and epigenetics. Review of General Psychology, 13(3): $194-201$.

Mayer, W., Niveleau, A., Walter, J., Fundele, R., and Haaf, T. (2000). Demethylation of the zygotic paternal genome. Nature, 403(6769): 501-502.

McGowan, P. O., Sasaki, A., Huang, T. C. T., Unterberger, A., Suderman, M., Ernst, C. et al. (2008). Promoter-wide hypermethylation of the ribosomal RNA gene promoter in the suicide brain. PlOS ONE, 3(5): e2085.

Ordovás, J. M., and Smith, C. E. (2010). Epigenetics and cardiovascular disease. Nature Reviews Cardiology, 7(9): 510-519.

Painter, R. C., Osmond, C., Gluckman, P., Hanson, M., Phillips, D. I. W., and Roseboom, T. J. (2008). Transgenerational effects of prenatal exposure to the Dutch famine on neonatal adiposity and health in later life. BJOG : An International Journal of Obstetrics and Gynaecology, 115(10): 1243-1249.

Pembrey, M. E. (2002). Time to take epigenetic inheritance seriously. European Journal of Human Genetics, 10(11): 669-671. 
Pembrey, M. E. (2010). Male-line transgenerational responses in humans. Human Fertility, 13(4): 268-271.

Pembrey, M. E., Bygren, L. O., Kaati, G., Edvinsson, S., Northstone, K., Sjöström, M. et al. (2006). Sex-specific, male-line transgenerational responses in humans. European Journal of Human Genetics, 14(2): 159-166.

Radtke, K. M., Ruf, M., Gunter, H. M., Dohrmann, K., Schauer, M., Meyer, A. et al. (2011). Transgenerational impact of intimate partner violence on methylation in the promoter of the glucocorticoid receptor. Translational Psychiatry, 1(7): e21.

Raico, R. (1989). The politics of hunger: a review. The Review of Austrian Economics, 3(1): 253-259.

Roesle, E. E. (1928). Die Geburts- und Sterblichkeitsverhltnisse. In Bumm, F. (Ed.). Deutschlands Gesundheitsverhltnisse unter dem Einfluss des Weltkrieges (Vol. 7). Deutsche Verlags-Anstalt.

Scholte, R., van den Berg, G. J. and Lindeboom, M. (2012). Long-run effects of gestation during the Dutch hunger winter famine on labor market and hospitalization outcomes. IZA Working Papers, (6307).

Sparén, P., Vagerö, D., Shestov, D. B., Plavinskaja, S., Parfenova, N., Hoptiar, V. et al. (2004). Long term mortality after severe starvation during the siege of Leningrad: prospective cohort study. British Medical Journal, 328(7430): 11.

Starling, E. H. (1919). Report on Food Conditions in Germany. HMSO.

Steckel, R. H. (2008). Biological measures of the standard of living. The Journal of Economic Perspectives, 22(1): 129-152.

Sunder, M., and Woitek, U. (2005). Boom, bust, and the human body: further evidence on the relationship between height and business cycles. Economics \& Human Biology, 3(3): 450-466.

Tobi, E. W., Lumey, L. H., Talens, R. P., Kremer, D., Putter, H., Stein, A. D. et al. (2009). DNA methylation differences after exposure to prenatal famine are common and timingand sex-specific. Human Molecular Genetics, 18(21): 4046-4053.

van den Berg, G. J., Doblhammer-Reiter, G., and Christensen, K. (2011). Being born under adverse economic conditions leads to a higher cardiovascular mortality rate later in life: evidence based on individuals born at different stages of the business cycle. Demography, 48(2): 507-530.

van den Berg, G. J., Lundborg, P., Nystedt, P., and Rooth, D.-O. (2009). Critical periods during childhood and adolescence: A study of adult height among immigrant siblings. 
IZA Working Papers, (4140).

van den Berg, G. J., Pinger, P. R., and Schoch, J. (2011). Instrumental variable estimation of the causal effect of hunger early in life on health later in life. IZA Working Papers, (6110).

Vincent, C. (1985). The Politics of Hunger: The Allied Blockade of Germany, 1915-1919. Ohio University Press.

Waaler, H. (1984). Height, weight and mortality - the Norwegian experience. Acta Medica Scandinavica, 215(S679): 1-56.

Wagner, G. G., Frick, J. R., and Schupp, J. (2007). The German socio-economic panel study (SOEP) - scope, evolution and enhancements. Schmollers Jahrbuch, 127(1): 139-169.

Witte, W. (2008). Tollkirschen und Quarantäne: Die Geschichte der Spanischen Grippe. Wagenbach.

Woitek, U. (2003). Height cycles in the 18th and 19th centuries. Economics \& Human Biology, 1(2): 243-257.

Zeisel, S. H. (2007). Nutrigenomics and metabolomics will change clinical nutrition and public health practice: insights from studies on dietary requirements for choline. American Journal of Clinical Nutrition, 86(3): 542-548. 


\section{Appendix}

Table A. 1: Food consumption before and during the famine (percent of pre-war level)

\begin{tabular}{l|ccc}
\hline Item & $\begin{array}{c}\text { July 1916 } \\
\text { until June 1917 }\end{array}$ & $\begin{array}{c}\text { July 1917 } \\
\text { until June } 1918\end{array}$ & $\begin{array}{c}\text { July } 1918 \\
\text { until December } 1918\end{array}$ \\
\hline Meat & 31 & 20 & 12 \\
Fish & 51 & - & 5 \\
Eggs & 18 & 13 & 15 \\
Lard & 14 & 11 & 7 \\
Butter & 22 & 21 & 28 \\
Cheese & 3 & 4 & 15 \\
Rice & 4 & - & - \\
Pulse & 14 & 1 & 80 \\
Sugar & 49 & $56-67$ & 17 \\
Vegetable oil & 39 & 41 & 94 \\
Potatoes & 71 & 94 & 48 \\
Flour & 53 & 47 & \\
\hline
\end{tabular}

Sources:

reprinted from Arnulf Huegel, 2003, Kriegsernährungswirtschaft Deutschlands während des Ersten und Zweiten Weltkrieges im Vergleich (pp 180). 
Table A. 2: Prices for foodstuffs in Bonn (in Mark), 1914 to 1918

\begin{tabular}{rrrrrr}
\hline Product & Unit & $\begin{array}{r}\text { Official } \\
1914\end{array}$ & $\begin{array}{r}\text { Official } \\
1917 / 18\end{array}$ & $\begin{array}{r}\text { Black market } \\
1917 / 1918\end{array}$ & $\begin{array}{r}\text { Increase } \\
(\%)\end{array}$ \\
\hline Beef & $1 \mathrm{lb}$ & 1 & 2.8 & 4.75 & 375 \\
Veal & $1 \mathrm{lb}$ & 1 & 2.8 & 5 & 400 \\
Pork & $1 \mathrm{lb}$ & 0.8 & - & 6 & 650 \\
Gammon & $1 \mathrm{lb}$ & 1.2 & - & 13 & 983 \\
Bacon & $1 \mathrm{lb}$ & 0.7 & 2.75 & 15.5 & 2.114 \\
Suet & $1 \mathrm{lb}$ & 0.4 & 2 & 14.5 & 3.525 \\
Lard & $1 \mathrm{lb}$ & 0.8 & 5 & 18 & 2.15 \\
Butter & $1 \mathrm{lb}$ & 1.3 & 3.4 & 4.5 & 800 \\
Curd & $1 \mathrm{lb}$ & 0.2 & 2.3 & 14 & 977 \\
Eggs & $1 \mathrm{p}$ piece & 0.06 & 0.4 & 3.5 & 1.65 \\
Colza oil & $1 \mathrm{l}$ & 0.6 & 5 & 0.65 & 983 \\
Salad oil & $1 \mathrm{l}$ & 1.4 & - & 21.5 & 3.483 \\
Olive oil & $1 \mathrm{l}$ & 3 & - & 24 & 1.614 \\
Rye flour & $1 \mathrm{lb}$ & 0.15 & 1.85 & 50 & 1.567 \\
Wheat flour & $1 \mathrm{lb}$ & 0.2 & - & 4 & 2.567 \\
Rice & $1 \mathrm{lb}$ & 0.25 & - & 4 & 1.9 \\
\hline
\end{tabular}

Source:

reprinted from Blum, 2011 (original source Roerkohl, Anne, 1991), Government decisions before and during World War I and the living standards in Germany during a drastic natural experiment (p. $558)$. 